\title{
3 Research Square

\section{Analysis of spot urine biomarkers and association with body weight in Japanese elementary school children}

\section{Nozomi Takemoto}

University of the Ryukyus Faculty of Medicine Graduate School of Medicine: Ryukyu Daigaku Igakubu Daigakuin Igaku Kenkyuka

\section{Jasmine Millman}

University of the Ryukyus Faculty of Medicine Graduate School of Medicine: Ryukyu Daigaku Igakubu Daigakuin Igaku Kenkyuka

\section{Fusae Yamakawa}

University of the Ryukyus Faculty of Medicine Graduate School of Medicine: Ryukyu Daigaku Igakubu Daigakuin Igaku Kenkyuka

\section{Tsugumi Uema}

University of the Ryukyus Faculty of Medicine Graduate School of Medicine: Ryukyu Daigaku Igakubu Daigakuin Igaku Kenkyuka

\section{Shiki Okamoto}

University of the Ryukyus Faculty of Medicine Graduate School of Medicine: Ryukyu Daigaku Igakubu Daigakuin Igaku Kenkyuka

\section{Mari Mori}

Tokai University: Tokai Daigaku

\section{Hideki Mori}

Mukogawa Women's University: Mukogawa Joshi Daigaku

\section{Koshi Nakamura}

University of the Ryukyus Faculty of Medicine Graduate School of Medicine: Ryukyu Daigaku Igakubu Daigakuin Igaku Kenkyuka

\section{Yukio Yamori}

Mukogawa Women's University: Mukogawa Joshi Daigaku

\section{Hiroaki Masuzaki ( $\nabla$ hiroaki@med.u-ryukyu.ac.jp )}

University of the Ryukyus Faculty of Medicine Graduate School of Medicine: Ryukyu Daigaku Igakubu Daigakuin Igaku Kenkyuka

\section{Research Article}

Keywords: Spot urine, Salt, Magnesium, Body mass index, Obesity 
Posted Date: March 1st, 2022

DOI: https://doi.org/10.21203/rs.3.rs-1394243/v1

License: (c) (i) This work is licensed under a Creative Commons Attribution 4.0 International License. Read Full License 


\section{Abstract \\ Purpose}

Childhood obesity is rapidly increasing world-wide and is largely the consequence of adoption of unhealthy diets excessive in calories and salt $(\mathrm{NaCl})$ as well as devoid in pivotal micronutrients such as potassium ( $\mathrm{K}$ ) and magnesium $(\mathrm{Mg})$. Education-based programs aiming to encourage healthy food knowledge and behaviors are crucial at a young age, and for this purpose, convenient ways to assess daily dietary intake are warranted. We therefore attempted to evaluate the dietary intake of Okinawan school children in Japan by analyzing a series of biomarkers in morning spot urine samples and explore whether these biomarkers correlate with body weight and a series of metabolic parameters.

\section{Methods}

We enrolled 98 third-grade elementary school children in Okinawa, Japan. Morning spot urine samples were collected and analysed using high performance liquid chromatography (HPLC) to assess dietary intake.

\section{Results}

We found that estimated daily $\mathrm{NaCl}$ intake was higher in obese/overweight children as compared to healthy-weight children $(p=0.0001)$. There was also a significant positive correlation between body mass index (BMI) and $\mathrm{NaCl}$ intake (Spearman) $(\rho=0.45, p<0.0001)$ and a negative correlation between BMI and $\mathrm{Mg} / \mathrm{Cr}(\rho=-0.27, p=0.01)$. Furthermore, $\mathrm{Na} / \mathrm{K}$ ratio was higher in samples collected on Monday (weekend) as compared to samples collected on Thursday or Friday (weekday) $(p<0.0001)$.

\section{Conclusion}

Via the use of morning spot urine analyses, our results show that $\mathrm{NaCl}$ intake was associated with obesity, and Mg excretion negatively correlated with BMI in Japanese school children, highlighting the potential role of these micronutrients in maintaining a healthy body weight.

\section{What Is Known}

- Overweight and obesity is largely due to excessive consumption of calories and positively correlated with salt ( $\mathrm{NaCl}$ ) intake.

- Spot urine methods are convenient for assessing the nutritional needs and targeting prevention programs in children. 


\section{What is New}

- Utilizing morning spot urine analyses, estimated $\mathrm{NaCl}$ intake is positively correlated and $\mathrm{Mg} / \mathrm{Cr}$ negatively correlated with BMI in Okinawan school children.

- As estimated via morning spot urine samples, a greater proportion of children likely exceed recommended $\mathrm{NaCl}$ intake on the weekend as compared to weekday.

\section{Introduction}

The prevalence of childhood obesity has been swiftly increasing world-wide. Recent global estimates suggest that approximately 340 million children and adolescents aged 5-19 years are classified as overweight or obese [1], with several studies reporting that approximately $40-50 \%$ of obese children go onto develop obesity later in adulthood [2-4], putting this group at an elevated risk for developing type 2 diabetes and related cardiometabolic diseases later in life [5].

Although Japan has experienced a relatively low prevalence of obesity compared to other developed countries, Okinawa, a prefecture in the southernmost part of Japan, once renowned as being home to some of the healthiest and longest living people in the world, is now facing a stark increase in obesity and metabolic diseases in both adults and children [6]. This undesirable trend has resulted in an expedition decline in life expectancy in Okinawan people [7]. According to the School Health Survey Japan, approximately $9.2 \%$ of 8-year-old boys and girls in Okinawa are obese [8], which is considerably higher compared to the national average of $8.2 \%$ (boy) and $6.9 \%$ (girl) [9]. Reasons for such an alarming figure largely stem from westernization of the food culture, with increased availability and consumption of energy-dense, high salt (sodium chloride, $\mathrm{NaCl}$ ) containing foods such as fried foods and pastries and displacement of the traditional Okinawan diet naturally abundant in micronutrient-rich plant foods such as seaweeds, sweet potato, soy products, and moderate amounts of fish and seafood [7].

Excessive intake of $\mathrm{NaCl}$ is one of the main dietary factors diving increases in high blood pressure and cardiovascular diseases [10], with its intake found to be positively correlated with BMI independent of energy intake in adults [11]. Currently, Japanese people typically consume $10 \mathrm{~g}$ per day of $\mathrm{NaCl}$, more than twice as much as the upper $5 \mathrm{~g}$ daily limit advised by the World Health Organization $[12,13]$. Along with reducing $\mathrm{NaCl}$, increasing intake of micronutrients such as potassium and magnesium can also positively impact blood pressure and associated disease risks [14]. Given that obesity and related diseases often start to develop in early childhood, methods that accurately capture dietary intake profile and are easy to implement are warranted for assessing the nutritional needs and appropriately targeting prevention programs.

Although accurate execution of dietary records and food frequency questionnaire methods require both skilled professionals and participant's cooperation, assessment of biomarkers in urine offers a convenient and reliable alternative to assess dietary intake of specific nutrients, especially as a public health strategy [12]. In this context, we aimed to assess urinary biomarkers associated with nutrient 
intake utilizing morning spot urine samples of Okinawan elementary school children and explore the potential links with obesity.

\section{Methods}

\section{Study design and participants}

The present study was carried out in a cross-sectional fashion, recruiting 231 third-grade elementary schoolchildren, 8-9 years old, from two elementary schools in Okinawa prefecture, Japan, from November 2019 to January 2020. A total of 98 children (49 boys and 49 girls) were enrolled and asked to provide spot urine samples at four time points as well as measuring anthropometric indices and blood pressure. We excluded 17 children ( 5 boys and 12 girls) who provided only one sample across the four time points. Consequently, the remaining 81 children ( 44 boys and 37 girls) were considered eligible study participants and included in the subsequent analyses.

Ethics approval was obtained by the Ryukyu University Human Research Ethics Committee (approval number: 360, 25 October 2019). Written informed consent was obtained from all participants and their parent (or legal guardians). This study was carried out in accordance with the Helsinki Declaration.

\section{Assessment of a series of biomarkers in urine}

Spot urine samples were collected on Monday mornings to assess weekend eating habits, and Thursday or Friday mornings to assess weekday eating habits. Urine samples were collected over a total of four time points; $1^{\text {st: }}$ Monday November $2019,2^{\text {nd. }}$ : Thursday or Friday, November 2019, $3^{\text {rd. }}$ : Monday January and 2020 and $4^{\text {th. }}$. Thursday or Friday, November 2020.

Each spot urine sample was collected in 10-mL tubes at participants' home, brought to each school and stored at a $4^{\circ} \mathrm{C}$. Samples were then transferred into either an 8-mL tubes or 1-mL tube. Eight-mL samples were stored at $4^{\circ} \mathrm{C}$ and $1-\mathrm{mL}$ samples were stored at $-80^{\circ} \mathrm{C}$. Eight-mL tube samples were sent to FALCO Biosystems, Ltd. (Tokyo, Japan) to determine the level of pH, urea nitrogen (UN), creatinine (Cr), sodium $(\mathrm{Na})$, potassium $(\mathrm{K})$ and magnesium $(\mathrm{Mg})$. One-mL tube samples were sent to Mukogawa Women's University (Hyogo, Japan) for analyses of isoflavones (Iso) and taurine (Tau) by HPLC. Briefly, HPLC analyses were performed to assess the urinary value of the common dietary isoflavonoids including daidzein, genistein, glycitein as previously described, and the sum of daidzein, genistein, glycitein and equol were calculated as the total concentration of Iso $[15,16]$. Salt intake $(\mathrm{NaCl}[\mathrm{g} /$ day] $)$ was estimated using Tanaka's equation [17].

\section{Measurements of Anthropometric indices and Blood pressure}

Body height and weight were measured, and body mass index (BMI) was computed as weight $(\mathrm{kg})$ per the square of height $(\mathrm{m})$. BMI values were converted to age-adjusted and sex-adjusted BMI z-scores from WHO References 2007 [18]. According to the WHO BMI-for-age growth charts, children were classified as 
underweight (less than -2SD), normal weight (-2SD to less than 1SD), overweight (1SD, equivalent to BMI $25 \mathrm{~kg} / \mathrm{m}^{2}$ at 19 years, to less than 2SD) or obese (over 2SD, equivalent to BMI $30 \mathrm{~kg} / \mathrm{m}^{2}$ at 19 years). Blood pressure (BP) was measured in the seated position using an automatic manometer (HBP-1300, Omron Healthcare Co., Ltd, Kyoto, Japan) on three separate occasions over the course of the study by trained researchers.

\section{Statistical Analysis}

For participants providing multiple urine samples, we calculated the average of concentration of specific biomarkers from $1^{\text {st }}$ and $3^{\text {rd }}$ urine samples on Monday to assess weekend dietary intake (A), and the average of concentration of specific biomarkers from $2^{\text {nd }}$ and $4^{\text {th }}$ urine samples on either Thursday or Friday to assess weekday dietary intake (B). For participants providing a single urine sample on either $1^{\text {st }}$ or $3^{\text {rd }}$ time point, as well as on either $2^{\text {nd }}$ or $4^{\text {th }}$ time point, the concentration of specific urinary biomarkers from the single urine sample were used for $(A)$ and $(B)$, respectively. Taken together, we used the average of $(A)$ and $(B)$ as the result of specific urinary biomarkers and $\mathrm{NaCl}$.

Data regarding subject characteristics are presented collectively as well as separately for boys and girls. Urinary biomarkers were also compared between healthy weight and obese/overweight children and are shown. Data are expressed as mean \pm standard deviation or median and $25^{\text {th }}$ and $75^{\text {th }}$ percentiles. Unpaired $t$-test was used for normal distribution data, while Wilcoxon test was used for skewed distribution data. Spearman's rank correlation coefficients were used to assess correlations between each urinary biomarker and BMI. A similar correlation method was performed as a sensitivity analysis utilizing participants' urine samples that were collected across all of four time points. Finally, biomarkers in urine samples were compared between weekend and weekday to examine whether variation of eating habits may be potentially influenced by school lunch or 'Kyushoku'.

All probability values were two-tailed, and the significance level was set at $p<0.05$. All statistical analyses were carried out using standard software packages (JMP pro version 15; SAS Institute Inc., Cary, NC, USA).

\section{Results}

\section{Characteristics of study participants}

The average weight of the children was $29.4 \pm 5.5 \mathrm{~kg}$, and the average height was $131.6 \pm 5.8 \mathrm{~cm}$, respectively. No statistical differences in parameters were observed between boys and girls (Table 1 ). According to BMI z-score, 4 boys were classed as obese, and 6 boys and 3 girls were classed as overweight. There were no participants classed as underweight. However, some urinary biomarkers reflecting dietary intake showed statistically significant differences between boys and girls, including $\mathrm{Na} / \mathrm{Cr}$ (boys $124.2 \mathrm{mEq} / \mathrm{gCr}$ versus girls $109.0 \mathrm{mEq} / \mathrm{gCr}, p=0.01$ ) and $\mathrm{K} / \mathrm{Cr}$ (boys $28.5 \mathrm{mEq} / \mathrm{gCr}$ versus girls $23.8 \mathrm{mEq} / \mathrm{gCr}, p=0.0085$ ) (Table 2). 


\section{Anthropometric indices and urinary biomarkers}

Table 3 shows anthropometric indices and blood pressure comparing healthy weight with obese/overweight children. Statistically significant differences were observed not only for weight, but also for height (healthy weight: $130.8 \mathrm{~cm}$ versus obese/overweight: $135.7 \mathrm{~cm}, p=0.0053$ ) (Table 3). However, blood pressure levels were apparently similar for healthy weight and obese/overweight children. $\mathrm{NaCl}$ intake was significantly different between healthy weight and obese/overweight children (healthy weight: $4.7 \mathrm{~g} /$ day versus obesity/overweight:6.0g/day, $p=0.0001$ ) (Table 4). As illustrated in Fig. 1, there was a positive correlation between BMI and $\mathrm{NaCl}(\rho=0.45, p<0.0001)$ (Fig. 1a) and a negative correlation between $\mathrm{BMI}$ and urinary $\mathrm{Mg} / \mathrm{Cr}(\rho=-0.27, p=0.01)$ (Fig. 1b).

When performing a sensitivity analysis using only biomarker data from subjects' urine samples that were collected across all four time points $(n=42)$, a moderate positive correlation between $\mathrm{BMI}$ and $\mathrm{NaCl}$ $(\rho=0.61, p<0.0001)$ and slightly negative correlation between BMl and urinary $\mathrm{Mg} / \mathrm{Cr}(\rho=-0.23, p=0.14)$ was found.

\section{Measurement of urinary biomarkers across time points}

Both $\mathrm{Na} / \mathrm{Cr}$ excretion level and $\mathrm{Na} / \mathrm{K}$ ratio were significantly elevated in weekend as opposed to weekday samples (Na/Cr: $130.6 \mathrm{mEq} / \mathrm{gCr}$ versus $107.6 \mathrm{mEq} / \mathrm{gCr}, p<0.0001 \rrbracket$, $(\mathrm{Na} / \mathrm{K}: 5.4$ versus $3.8, p<0.0001 \rrbracket$, and Iso/Cr excretion level was significantly lower in weekend as compared to weekday samples (12.5 $\mathrm{nmol} / \mathrm{mgCr}$ versus $21.5 \mathrm{nmol} / \mathrm{mgCr}, p=0.0047$ ) (Table 5). Although there were no statistically significant differences in estimated $\mathrm{NaCl}$ intake between weekend and weekday samples, the percentage of participants with $\mathrm{NaCl}$ intake estimated at $\geq 5 \mathrm{~g} /$ day was apparently greater in weekend as compared to weekday samples (weekend $54 \%$ versus weekday $38 \%$ ) (Fig. 2).

\section{Discussion}

The present study showed a moderately significant positive correlation between $\mathrm{NaCl}$ intake and $\mathrm{BMI}$, and a slightly significant negative correlation between $\mathrm{Mg} / \mathrm{Cr}$ excretion and $\mathrm{BMI}$ in Okinawan school children. Research in pooled urine samples in humans has demonstrated that Na concentration reflects salt intake, $\mathrm{K}$ concentration reflects the intake of vegetables and fruits, and $\mathrm{Mg}$ concentration reflects the intake of unrefined whole grains such as brown rice, seeds and seaweeds [19-21]. Although 24-hour urine collection has been the standard that accurately captures the profile of dietary intake, in recent years, it has been reported that highly reproducible results can be obtained with spot urine collection and analytic methodologies [17, 22-24]. Based on these notions, in the present study of spot urine analyses, we did observe a number of significant differences in measurements of specific urinary biomarkers and estimated dietary micronutrient intakes in Okinawan school children when considering gender, $\mathrm{BMI}$ and weekend versus weekday sampling. Regarding gender differences, boys showed a significantly higher value of urinary $\mathrm{Na} / \mathrm{Cr}$ and $\mathrm{K} / \mathrm{Cr}$ than girls. These results are in agreement with a larger sized study which recruited 766 Italian boys and 658 girls aged 6-18 years at National Health Service Centers across 10 regions, and 24-hour urine collection found that boys across all developmental ages showed a 
significantly higher value of estimated $\mathrm{NaCl}$ and $\mathrm{K}$ intakes than girls [20]. As the children in our study were of pre-pubescent age, it is unlikely that such a gender dimorphism is due to sexual development or subsequent influence of sex hormones, but presumably more so a consequence of the increased amount of food boys consume as compared to girls [25].

When stratified subjects according to BMI in spot urine analyses, we observed significantly lower urine $\mathrm{pH}$ and significantly higher estimated $\mathrm{NaCl}$ intake in obese/overweight children compared to healthy weight children. In support of this, a cross-sectional study employing 5,430 Japanese subjects using fasting single spot urine found that subjects with components of the Metabolic Syndrome were significantly associated with lower urine $\mathrm{pH}$ [26]. On top of this, 524 children (aged 6-17 years) in the DOrtmund Nutritional and Anthropometric Longitudinally Designed (DONALD) Study in Germany also reported a significant inverse relationship with fat mass and urinary $\mathrm{pH}$ [27]. Concerning the elevated $\mathrm{NaCl}$ intake in obese/overweight children observed in our study, this is in line with a number of previous studies showing that $\mathrm{NaCl}$ intake is higher in obese and overweight adults as well as children [28-32].

Following on from this point, level of estimated $\mathrm{NaCl}$ intake in spot urine analyses was positively associated with BMI in Okinawan school children. This finding is consistent with a number of previous larger, population-based studies in adults showing that $\mathrm{NaCl}$ excretion was positively associated with body weight as well as central obesity even after controlling for energy intake [33-35]. Other previous studies also observed the same results in children [36,37]. Specifically, a large study with 1,738 boys aged 10-18 years from the Korea National Health and Nutrition Examination found that subjects in the highest quartile for urinary sodium excretion to urinary gravity specific ratio (a representative for sodium intake) showed significantly higher body weight, BMI and waist circumference among groups [37]. Also, in a cross-sectional study of 374 Iranian children aged $11-18$ years found that $24-\mathrm{h}$ urinary $\mathrm{Na} / \mathrm{K}$ ratio showed significantly positive associations with value of waist circumference and percentage of body fat even after adjusting for sugar sweetened beverage consumption or calorie intake [36]. Although our study cannot rule out the possibility that estimated higher $\mathrm{NaCl}$ intake in children with higher $\mathrm{BMI}$ is due to increased consumption of highly processed, energy dense foods, a line of plausible mechanisms have been proposed regarding the independent relationship between $\mathrm{NaCl}$ intake and overweight/obesity. Firstly, high $\mathrm{NaCl}$ intake is associated with increased urinary cortisol [38,39] also in children [40]. Mechanism-oriented studies in mice show that high $\mathrm{NaCl}$ intake can stimulate aldose reductasefructokinase pathway in both liver and hypothalamus, causing endogenous fructose production, subsequent leptin resistance and hyperphagia, resulting in obesity [41]. Such a mechanism has been commonly observed in humans with healthy subjects consuming diets high $\mathrm{NaCl}$, prone to developing type 2 diabetes and non-alcoholic fatty liver disease (NAFLD) [41].

Noticeably, we found that the $\mathrm{Mg}$ excretion levels in spot urine were inversely associated with $\mathrm{BMI}$ in Okinawan school children. These findings are also supported by previous population-based studies indicating that lower intake of $\mathrm{Mg}$ is associated with higher BMI [42-44]. Although there has not been enough data in children linking urinary excretion level of $\mathrm{Mg}$ with body weight, lower levels of serum $\mathrm{Mg}$ were shown to be significantly lower in both obese children and adolescents compared to healthy weight 
controls [45]. Several mechanisms are postulated as to how lower levels of $\mathrm{Mg}$ in urine samples may potentially relate with increased body weight. Firstly, $\mathrm{Mg}$ deficiency is tightly linked with an increase in a number of inflammatory markers including CRP and TNF-a in obese humans [46]. Mechanism-oriented studies in animals showed that $\mathrm{Mg}$ deficiency leads to an inflammatory response primarily via increasing intracellular calcium, which in turn causes priming of immune cells such as leukocytes and macrophages, resulting in a variety of inflammatory responses [47]. In addition, $\mathrm{Mg}$ is crucial for regulating several key enzymes involved in glucose metabolism [48]. In particular, Mg deficiency increases anaerobic metabolites such as lactate within adipocytes, leading to an increased triglyceride storage and insulin resistance in adipose tissue $[49,50]$.

Intriguingly in the present study, a significant increase in urinary sodium and $\mathrm{Na} / \mathrm{K}$ ratio as well as a significant decrease in level of urinary isoflavones were observed in the weekend compared to the weekday in spot urine samples. In support of our data, a study of Japanese preschool children employing spot urine collection found that the $\mathrm{Na}$ excretion level as well as $\mathrm{Na} / \mathrm{K}$ ratio was significantly higher on the weekend compared to the weekday [51]. Similarly, a cross-sectional study of Australian school children assessing electrolyte intake by 24 -hour urine discovered that $\mathrm{NaCl}$ intake was roughly $1.0 \mathrm{~g} /$ day higher on non-school days versus school days [52]. Regarding the analysis of other measured biomarkers in urine, weekend Iso excretion levels in our study were comparable to previous studies in Japanese preschool children reporting that mean Iso intakes range between $12 \mathrm{mg} / \mathrm{d}-14 \mathrm{mg} / \mathrm{d}$ [53]. This notion raises a possibility that weekday Iso levels are significantly higher due to the inclusion of school lunch or 'Kyushoku' featuring isoflavone-rich soy foods in Japan, thereby contributing to overall improved diet quality [54]. In contrast, our study in spot urine samples observed no statistically significant differences in taurine excretion levels, a validated biomarker of taurine-rich seafood and fish intake, between weekend and weekday samples. These findings may be a reflection of the substantial lack of seafood and fish featured in the diets of Okinawan school children both during the weekday including school lunches and also on weekends. In fact, a study assessing seafood intake as measured by urinary excretion of Tau in school children in mainland Japan showed that Tau/Cr level was higher compared to levels observed in our study [23].

There are a couple of limitations in the present study. Firstly, without collection of dietary intake data using validated assessment tools, we are unable to report on the intercorrelations among urinary biomarkers, dietary intake and level of obesity. However, it should be noted that our results are well consistent with previous studies that employed urine analyses in combination with validated dietary intake assessment tools $[43,44,54]$. Secondly, as this study was a cross-sectional, causal inference cannot be assumed regarding the temporal link between obesity and intake of specific micronutrients and also limited number of subjects reduced the power of the study. Finally, our study population was comprised of children residing in the southern island community of Japan with a distinctly different climate and culture compared to other Japanese communities and therefore should be taken this point into consideration. 


\section{Conclusion}

In Okinawan school children, high dietary intake of $\mathrm{NaCl}$ and low intake of $\mathrm{Mg}$ as estimated by spot urine analyses were significantly associated with body weight, suggesting a pivotal role of dietary electrolyte intake in the management of healthy body weight. Also, the lower dietary intake of $\mathrm{NaCl}$ on weekdays as opposed to weekends may suggest the positive influence of weekday school lunches in this population group. Overall, our results open up a potentially fresh avenue to expand food-based education programs in school children at the risk of obesity, further supporting the significance of Japanese school lunch in helping to improve the overall diet quality of children.

\section{Abbreviations}

BMI: Body mass index

BP: Blood pressure

UN: Urea nitrogen

Cr: Creatinine

CRP: C-reactive protein

HPLC: High performance liquid chromatography

Iso: Isoflavones

K: Potassium

Mg: Magnesium

$\mathrm{Na}$ : Sodium

$\mathrm{NaCl}$ : Sodium chloride (salt)

SD: Standard deviation

Tau: Taurine

TNF-a: Tumor necrosis factor-alpha

WHO: World Health Organization

\section{Declarations}


Acknowledgements: This work was supported in part by Health problem-solving support project of the Well-being Agency of Okinawa (2019-2020). We thank the board of education of Okinawa prefecture for introducing two elementary schools, and third-grade elementary school teachers and nursing teachers for enthusiastic support. We are grateful to T. Ikematsu, Y. Inamine, M. Hirata and C. Noguchi for secretarial assistance.

Conflict of Interest: None of authors have conflict of interest to disclose.

\section{Author contributions}

N.T. and J.M. wrote the manuscript. Material preparation and data collection were performed by N.T., F.Y. and T.U. Analysis of samples was conducted by M.M. and H.M. N.T. and F.Y. performed the statistical analyses, with supervision from K.N. S.O Y.Y. and H.M. supervised jointly supervised the study. All authors read and approved the final manuscript.

\section{Funding}

This work was supported in part by Health problem-solving support project of the Well-being Agency of Okinawa (2019-2020).

\section{Competing interests}

The authors have no relevant financial or non-financial interests to disclose.

\section{Availability of data and material}

The datasets generated during and/or analyzed during the current study are available from the corresponding authors on

reasonable request.

\section{Code availability}

Not applicable.

\section{Author contributions}

All authors contributed to the study conception and design. Material preparation and data collection were performed by Nozomi Takemoto, Fusae Yamakawa and Tsugumi Uema. Analysis of samples were conducted by Mari Mori and Hideki Mori. Statistical analyses were performed by Nozomi Takemoto and Fusae Yamakawa under the supervision of Koshi Nakamura. The first draft of the manuscript was written by Nozomi Takemoto and Jasmine Millman. Nozomi Takemoto, Jasmine Millman and Hiroaki Masuzaki reviewed and edited the final manuscript. Shiki Okamoto, Yukio Yamori and Hiroaki Masuzaki supervised the study. All authors read and approved the final manuscript. 


\section{Ethics approval}

This study was performed in line with the principles of the Declaration of Helsinki. Approval was granted by the Ethics Committee of the University of the Ryukyus (25 October 2019, approval number: 360 )

\section{Consent to participate}

Witten informed consent was obtained from the parents of children who participated in the study.

\section{Consent to publish}

Not applicable.

\section{References}

1. Nahhas MA, Asamoah F, Mullen S, Nwaru BI, Nurmatov U (2018) Epidemiology of overweight and obesity in early childhood in the Gulf Cooperation Council countries: a systematic review and metaanalysis protocol. BMJ Open 8(6): e019363. doi:10.1136/bmjopen-2017-019363

2. Mossberg H O (1989) 40-year follow-up of overweight children. Lancet 334: 491-3. doi:10.1016/s0140-6736(89)92098-9

3. Weihrauch-Blüher S, Wiegand S (2018) Risk Factors and Implications of Childhood Obesity. Curr Obes Rep 7:254-259. doi:10.1007/s13679-018-0320-0

4. Simmonds M, Llewellyn A, Owen CG, Woolacott N (2016) Predicting adult obesity from childhood obesity: a systematic review and meta-analysis. Obesity Reviews 17:95-107. doi: 10.1111/obr.12334.

5. Di Cesare M, Soric M, Bovet P, Miranda JJ, Bhutta Z, Stevens GA, Laxmaiah A, Kengne AP, Bentham J (2019) The epidemiological burden of obesity in childhood: a worldwide epidemic requiring urgent action. BMC Med 17:212. doi: 10.1186/s12916-019-1449-8.

6. Shirai K. Social Determinants of Health on the Island of Okinawa (2020). In: Brunner E, Cable N and Iso H, Editors. Health in Japan. Oxford: Oxford University Press.

7. Willcox DC, Willcox BJ, Todoriki H, Suzuki M (2009) The Okinawan diet: health implications of a lowcalorie, nutrient-dense, antioxidant-rich dietary pattern low in glycemic load. Journal of the American College of Nutrition 28 Suppl:500s-516s. doi: 10.1080/07315724.2009.10718117.

8. Okinawa Prefectural Board of Education (2019) The School Health Survey Okinawa, Japan. https://www.pref.okinawa.lg.jp/edu/somu/documents/00r01 houkokusyoikkatu.pdf. Accessed 18 May 2020

9. Ministry of Education, Culture, Sports, Science and Technology (2019) The School Health Survey Japan. https://www.mext.go.jp/content/20200319-mxt_chousa01-20200319155353_1-3.pdf. Accessed 23 March 2020

10. Rust P, Ekmekcioglu C (2017) Impact of Salt Intake on the Pathogenesis and Treatment of Hypertension. Advances in experimental medicine and biology 956:61-84. doi: 
10.1007/5584_2016_147.

11. Ma Y, He FJ, MacGregor GA (2015) High salt intake: independent risk factor for obesity? Hypertension 66:843-849. doi: 10.1161/HYPERTENSIONAHA.115.05948.

12. Ministry of Health Labour and Welfare, Japan (2020) Dietary Reference Intakes for Japanese 2020. https://www.mhlw.go.jp/content/10904750/000586565.pdf. Accessed 24 December 2019

13. Uechi K, Asakura K, Masayasu S, Sasaki S (2017) Within-country variation of salt intake assessed via urinary excretion in Japan: a multilevel analysis in all 47 prefectures. Hypertens Res 40:598-605. doi: 10.1038/hr.2016.185.

14. Pickering RT, Bradlee ML, Singer MR, Moore LL (2021) Higher Intakes of Potassium and Magnesium, but Not Lower Sodium, Reduce Cardiovascular Risk in the Framingham Offspring Study. Nutrients 13. doi: 10.3390/nu13010269.

15. Group W-CS (1990) Excerpts from the WHO CARDIAC Study Protocol. J Cardiovasc Pharmacol 16:S75-S77

16. WHO (1986) Collaborating Center on Primary Prevention of Cardiovascular Diseases, Izumo, Japan and Cardiovascular Diseases Unit, WHO. Cardiovascular Diseases and Alimentary Comparison (CARDIAC) Study Protocol and Manual Operations. WHO: Shimane, Japan/Geneva, Switzerland.

17. Tanaka T, Okamura T, Miura K, Kadowaki T, Ueshima H, Nakagawa H, Hashimoto T (2002) A simple method to estimate populational 24-h urinary sodium and potassium excretion using a casual urine specimen. J Hum Hypertens 16:97-103. doi: 10.1038/sj.jhh.1001307.

18. De Onis M (2007) Development of a WHO growth reference for school-aged children and adolescents. Bulletin of the World Health Organization 85:660-667. doi: 10.2471/blt.07.043497.

19. Tang NLS, Chan YK, Hui E, Woo J (2000) Application of urine magnesium/creatinine ratio as an indicator for insufficient magnesium intake. Clin Biochem 33:675-678. doi: 10.1016/s00099120(00)00173-9.

20. Campanozzi A, Avallone S, Barbato A, lacone R, Russo O, De Filippo G, D'Angelo G, Pensabene L, Malamisura B, Cecere G, Micillo M, Francavilla R, Tetro A, Lombardi G, Tonelli L, Castellucci G, Ferraro L, Di Biase R, Lezo A, Salvatore S, Paoletti S, Siani A, Galeone D, Strazzullo P, Group M-GPS (2015) High sodium and low potassium intake among Italian children: relationship with age, body mass and blood pressure. PLoS One 10:e0121183. doi: 10.1371/journal.pone.0121183.

21. Hamada A, Taguchi T, Mori H, Thorpe M, Yamori Y, Mori M (2011) Possible association of high urinary magnesium and taurine to creatinine ratios with metabolic syndrome risk reduction in Australian aboriginals. Cardiol Res Pract 2011:235653. doi: 10.4061/2011/235653.

22. Iwahori T, Ueshima H, Miyagawa N, Ohgami N, Yamashita H, Ohkubo T, Murakami Y, Shiga T, Miura K (2014) Six random specimens of daytime casual urine on different days are sufficient to estimate daily sodium/potassium ratio in comparison to 7-day 24-h urine collections. Hypertens Res 37:765771. doi: 10.1038/hr.2014.76.

23. Mori M, Mori H, Hamada A, Yamori Y (2010) Taurine in morning spot urine for the useful assessment of dietary seafood intake in Japanese children and adolescents. J Biomed Sci 17 Suppl 1:S43. doi: 
10.1186/1423-0127-17-S1-S43.

24. Rios-Leyvraz M, Bovet P, Tabin R, Genin B, Russo M, Rossier MF, Bochud M, Chiolero A (2018) Urine Spot Samples Can Be Used to Estimate 24-Hour Urinary Sodium Excretion in Children. J Nutr 148:1946-1953. doi: 10.1093/jn/nxy211.

25. Collins ME (1991) Body figure perceptions and preferences among preadolescent children. The International journal of eating disorders 10:199-208. doi: 10.1002/1098-108X(199103)10:2<199::AIDEAT2260100209>3.0.CO;2-D.

26. Shimodaira M, Okaniwa S, Nakayama T (2017) Fasting Single-Spot Urine pH Is Associated with Metabolic Syndrome in the Japanese Population. Med Princ Pract 26:433-437. doi:

$10.1159 / 000481624$.

27. Hua Y, Krupp D, Esche J, Remer T (2019) Increased body fatness adversely relates to 24-hour urine $\mathrm{pH}$ during childhood and adolescence: evidence of an adipo-renal axis. Am J Clin Nutr 109:12791287. doi: 10.1093/ajcn/nqy379.

28. Grimes CA, Bolhuis DP, He FJ, Nowson CA (2016) Dietary sodium intake and overweight and obesity in children and adults: a protocol for a systematic review and meta-analysis. Systematic Reviews 5. doi: 10.1186/s13643-015-0175-3.

29. Ma Y, He FJ, Macgregor GA (2015) High Salt Intake. Hypertension 66:843-849. doi:10.1161/HYPERTENSIONAHA.115.05948.

30. Rafie N, Mohammadifard N, Khosravi A, Feizi A, Safavi SM (2017) Relationship of sodium intake with obesity among Iranian children and adolescents. Arya Atheroscler 13:1-6

31. Fang K, He Y, Fang Y, Lian Y (2021) Relationship of Sodium Intake with Overweight/Obesity among Chinese Children and Adolescents: Data from the CNNHS 2010-2012. Int J Environ Res Public Health 18. doi: 10.3390/ijerph18094551.

32. Zhao $Y$, Wang $L$, Xue $H$, Wang $H$, Wang $Y$ (2017) Fast food consumption and its associations with obesity and hypertension among children: results from the baseline data of the Childhood Obesity Study in China Mega-cities. BMC Public Health 17:933. doi: 10.1186/s12889-017-4952-x.

33. Nam GE, Kim SM, Choi MK, Heo YR, Hyun TS, Lyu ES, Oh SY, Park HR, Ro HK, Han K, Lee YK (2017) Association between 24-h urinary sodium excretion and obesity in Korean adults: A multicenter study. Nutrition 41:113-119. doi: 10.1016/j.nut.2017.04.006.

34. Lee J, Hwang Y, Kim KN, Ahn C, Sung HK, Ko KP, Oh KH, Ahn C, Park YJ, Kim S, Lim YK, Park SK (2018) Associations of urinary sodium levels with overweight and central obesity in a population with a sodium intake. BMC Nutr 4:47. doi: 10.1186/s40795-018-0255-6.

35. Zhou L, Stamler J, Chan Q, Van Horn L, Daviglus ML, Dyer AR, Miura K, Okuda N, Wu Y, Ueshima H, Elliott P, Zhao L, Group IR (2019) Salt intake and prevalence of overweight/obesity in Japan, China, the United Kingdom, and the United States: the INTERMAP Study. Am J Clin Nutr 110:34-40. doi: 10.1093/ajcn/nqz067.

36. Rafie N, Hamedani SG, Mohammadifard N, Feizi A, Safavi SM (2019) 24-h urinary sodium to potassium ratio and its association with obesity in children and adolescents. Eur J Nutr 58:947-953. 
doi: 10.1007/s00394-018-1645-x.

37. So CH, Jeong HR, Shim YS (2017) Association of the urinary sodium to urinary specific gravity ratio with metabolic syndrome in Korean children and adolescents: The Korea National Health and Nutrition Examination Survey 2010-2013. PLoS One 12:e0189934. doi:

10.1371/journal.pone.0189934.

38. Chen AX, Haas AV, Williams GH, Vaidya A (2020) Dietary sodium intake and cortisol measurements. Clinical endocrinology 93:539-545. Chen AX, Haas AV, Williams GH, Vaidya A (2020) Dietary sodium intake and cortisol measurements. Clinical endocrinology 93:539-545. doi: 10.1111/cen.14262.

39. Baudrand R, Campino C, Carvajal CA, Olivieri O, Guidi G, Faccini G, Vohringer PA, Cerda J, Owen G, Kalergis AM, Fardella CE (2014) High sodium intake is associated with increased glucocorticoid production, insulin resistance and metabolic syndrome. Clinical endocrinology 80:677-684. doi: $10.1111 /$ cen. 12225.

40. Torres SJ, Grimes C, Nowson CA, Jayasinghe SU, Bruce CR, Mason SA, He FJ, Turner Al (2019) Urinary sodium is positively associated with urinary free cortisol and total cortisol metabolites in a cross-sectional sample of Australian schoolchildren aged 5-12 years and their mothers. Br J Nutr 121:164-171. doi: 10.1017/S0007114518003148.

41. Lanaspa MA, Kuwabara M, Andres-Hernando A, Li N, Cicerchi C, Jensen T, Orlicky DJ, RoncalJimenez CA, Ishimoto T, Nakagawa T, Rodriguez-Iturbe B, MacLean PS, Johnson RJ (2018) High salt intake causes leptin resistance and obesity in mice by stimulating endogenous fructose production and metabolism. Proceedings of the National Academy of Sciences of the United States of America 115:3138-3143. doi: 10.1073/pnas.1713837115.

42. Jiang S, Ma X, Li M, Yan S, Zhao H, Pan Y, Wang C, Yao Y, Jin L, Li B (2020) Association between dietary mineral nutrient intake, body mass index, and waist circumference in U.S. adults using quantile regression analysis NHANES 2007-2014. PeerJ 8:e9127. doi: 10.7717/peerj.9127.

43. Yamori Y, Sagara M, Mizushima S, Liu L, Ikeda K, Nara Y, for the CSG (2015) An inverse association between magnesium in 24-h urine and cardiovascular risk factors in middle-aged subjects in 50 CARDIAC Study populations. Hypertension Research 38:219-225. doi: 10.1038/hr.2014.158.

44. Lu L, Chen C, Yang K, Zhu J, Xun P, Shikany JM, He K (2020) Magnesium intake is inversely associated with risk of obesity in a 30-year prospective follow-up study among American young adults. Eur J Nutr 59:3745-3753. doi: 10.1007/s00394-020-02206-3.

45. Celik N, Andiran N, Yilmaz AE (2011) The relationship between serum magnesium levels with childhood obesity and insulin resistance: a review of the literature. Journal of pediatric endocrinology \& metabolism : JPEM 24:675-678.

46. Nielsen FH (2010) Magnesium, inflammation, and obesity in chronic disease. Nutr Rev 68:333-340. doi: $10.1111 / \mathrm{j} .1753-4887.2010 .00293$.

47. Nielsen FH (2018) Magnesium deficiency and increased inflammation: current perspectives. J Inflamm Res 11:25-34. doi: 10.2147/JIR.S136742. eCollection 2018. 
48. Garfinkel L, Garfinkel D (1985) Magnesium regulation of the glycolytic pathway and the enzymes involved. Magnesium 4:60-72

49. Piuri G, Zocchi M, Della Porta M, Ficara V, Manoni M, Zuccotti GV, Pinotti L, Maier JA, Cazzola R (2021) Magnesium in Obesity, Metabolic Syndrome, and Type 2 Diabetes. Nutrients 13. doi: $10.3390 /$ nu13020320.

50. Maguire D, Talwar D, Shiels PG, McMillan D (2018) The role of thiamine dependent enzymes in obesity and obesity related chronic disease states: A systematic review. Clin Nutr ESPEN 25:8-17. doi: 10.1016/j.clnesp.2018.02.007.

51. Yasutake K, Nagafuchi M, Izu R, Kajiyama T, Imai K, Murata Y, Ohe K, Enjoji M, Tsuchihashi T (2017) Sodium and potassium urinary excretion levels of preschool children: Individual, daily, and seasonal differences. J Clin Hypertens (Greenwich) 19:577-583. doi: 10.1111/jch.12966.

52. Grimes CA, Riddell LJ, Campbell KJ, Beckford K, Baxter JR, He FJ, Nowson CA (2017) Dietary intake and sources of sodium and potassium among Australian schoolchildren: results from the crosssectional Salt and Other Nutrients in Children (SONIC) study. BMJ Open 7:e016639. doi: 10.1136/bmjopen-2017-016639.

53. Messina M, Rogero MM, Fisberg M, Waitzberg D (2017) Health impact of childhood and adolescent soy consumption. Nutr Rev 75:500-515. doi: 10.1093/nutrit/nux016.

54. Asakura K, Sasaki S (2017) School lunches in Japan: their contribution to healthier nutrient intake among elementary-school and junior high-school children. Public Health Nutr 20:1523-1533. doi: $10.1017 /$ S1368980017000374.

\section{Tables}

Table 1 Characteristics of the study participants 


\begin{tabular}{|c|c|c|c|c|}
\hline & Total $(n=81)$ & Boys $(n=44)$ & Girls $(n=37)$ & $p$ value \\
\hline Height (cm) & $131.6 \pm 5.8$ & $131.6 \pm 6.1$ & $131.7 \pm 5.5$ & 0.93 \\
\hline Weight (kg) & $29.4 \pm 5.5$ & $30.1 \pm 6.4$ & $28.6 \pm 4.0$ & 0.21 \\
\hline $\mathrm{BMI}\left(\mathrm{kg} / \mathrm{m}^{2}\right)$ & $16.9 \pm 2.2$ & $17.2 \pm 2.6$ & $16.4 \pm 1.6$ & 0.10 \\
\hline BMI z-score ${ }^{a}$ & $0.16 \pm 1.0$ & $0.3 \pm 1.1$ & $-0.05 \pm 0.8$ & 0.09 \\
\hline Obese $(n)^{\mathrm{b}}$ & 4 & 4 & 0 & \\
\hline Overweight $(n)^{\mathrm{c}}$ & 9 & 6 & 3 & \\
\hline Underweight $(n)^{\mathrm{d}}$ & 0 & 0 & 0 & \\
\hline Systolic BP (mmHg) & $104 \pm 9$ & $105 \pm 9$ & $103 \pm 9$ & 0.32 \\
\hline Diastolic BP (mmHg) & $57 \pm 6$ & $57 \pm 7$ & $57 \pm 6$ & 0.70 \\
\hline
\end{tabular}

Values are shown as Mean \pm Standard Deviation (SD). Unpaired $t$-test was used to compare each characteristic in each sex group.

a BMI values were converted to age-adjusted and sex-adjusted BMI z-score according to WHO 2007

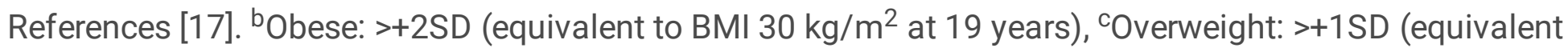
to BMI $25 \mathrm{~kg} / \mathrm{m}^{2}$ at 19 years), dUnderweight: <-2sd

Table 2 Urine biomarkers and estimated salt $(\mathrm{NaCl})$ intake in boys and girls 


\begin{tabular}{|c|c|c|c|c|}
\hline & Total $(n=81)$ & Boys $(n=44)$ & Girls $(n=37)$ & $p$ value \\
\hline $\mathrm{pH}$ & $6.0(5.875-6.25)$ & $6.0(5.875-6.26)$ & $6.0(5.8125-6.4375)$ & 0.68 \\
\hline $\mathrm{UN}(\mathrm{mg} / \mathrm{dL})$ & $1234.8 \pm 271.0$ & $1269.8 \pm 284.9$ & $1193.2 \pm 251.0$ & 0.21 \\
\hline $\mathrm{Cr}(\mathrm{mg} / \mathrm{dL})$ & $120.7 \pm 37.8$ & $114.3 \pm 36.6$ & $128.3 \pm 6.3$ & 0.10 \\
\hline $\mathrm{Na} / \mathrm{Cr}(\mathrm{mEq} / \mathrm{gCr})$ & $118.2(93.0-156.3)$ & $124.2(98.4-174.4)$ & $109.0(78.8-131.1)$ & 0.01 \\
\hline $\mathrm{K} / \mathrm{Cr}(\mathrm{mEq} / \mathrm{gCr})$ & $25.5(21.5-38.5)$ & $28.5(22.9-42.1)$ & $23.8(20.6-29.6)$ & 0.0085 \\
\hline $\mathrm{Mg} / \mathrm{Cr}(\mathrm{mEq} / \mathrm{gCr})$ & $13.7(11.7-16.2)$ & $13.7(11.3-17.0)$ & $13.4(11.9-15.7)$ & 0.99 \\
\hline $\mathrm{NaCl}$ (g/day) & $5.0(4.3-5.9)$ & $5.1(4.3-6.4)$ & $4.6(4.3-5.6)$ & 0.07 \\
\hline $\mathrm{Na} / \mathrm{K}$ & $4.6(3.7-6.4)$ & $4.6(3.7-6.2)$ & $4.6(3.6-6.4)$ & 0.95 \\
\hline & Total $(n=75)$ & Boys $(n=42)$ & Girls $(n=33)$ & $p$ value \\
\hline Iso/Cr (nmol/mgCr) & $19.1(10.3-34.6)$ & $18.2(10.1-37.4)$ & $19.8(11.2-32.7)$ & 0.75 \\
\hline $\begin{array}{l}\mathrm{Tau} / \mathrm{Cr} \\
\text { (nmol/mgCr) }\end{array}$ & $\begin{array}{l}762.5(550.0- \\
1040.4)\end{array}$ & $\begin{array}{l}737.8(497.1- \\
985.3)\end{array}$ & $\begin{array}{l}766.7(569.4- \\
1065.1)\end{array}$ & 0.41 \\
\hline
\end{tabular}

Values are presented as Median ( $25^{\text {th }}$ and $75^{\text {th }}$ percentiles) or Mean \pm Standard Deviation (SD). Wilcoxon test or unpaired $t$-test were used to compare each characteristic in each sex group.

Table 3 Characteristics of obese/overweight and healthy-weight children 


\begin{tabular}{|llll|}
\hline & Obese/overweight $(n=13)$ & Healthy-weight $(n=68)$ & $p$ value \\
\hline Height $(\mathrm{cm})$ & $135.7 \pm 4.0$ & $130.8 \pm 5.8$ & 0.0053 \\
\hline Weight $(\mathrm{kg})$ & $38.7 \pm 4.9$ & $27.6 \pm 3.4$ & \\
\hline BMI $\left(\mathrm{kg} / \mathrm{m}^{2}\right)$ & $210 . \pm 1.7$ & $16.1 \pm 1.2$ & $<0.0001$ \\
\hline BMI z-score & & $<0.0001$ \\
& $1.9 \pm 0.6$ & $-0.2 \pm 0.7$ & $<0.0001$ \\
\hline Systolic BP $(\mathrm{mmHg})$ & $106 \pm 9$ & & 0.41 \\
\hline Diastolic BP $(\mathrm{mmHg})$ & $58 \pm 6$ & $104 \pm 9$ & 0.68 \\
\hline
\end{tabular}

Values are shown as Mean \pm Standard Deviation (SD). Unpaired $t$-test were used to compare each characteristic in each weight group.

${ }^{\mathrm{a}} \mathrm{BMI}$ values were converted to age-adjusted and sex-adjusted BMI z-score according to WHO 2007 References [18].

Table 4 Selected urine biomarkers and estimated salt $(\mathrm{NaCl})$ intake in obese/overweight and healthyweight children 


\begin{tabular}{|c|c|c|c|}
\hline & Obese/overweight ( $n=13)$ & Healthy-weight $(n=68)$ & $p$ value \\
\hline $\mathrm{pH}$ & $6.0(5.625-6.0)$ & $6.0(5.875-6.25)$ & 0.01 \\
\hline $\mathrm{UN}(\mathrm{mg} / \mathrm{dL})$ & $1301.6 \pm 316.1$ & $1222.1 \pm 262.2$ & 0.33 \\
\hline $\mathrm{Cr}(\mathrm{mg} / \mathrm{dL})$ & $122.6 \pm 34.4$ & $120.4 \pm 38.7$ & 0.85 \\
\hline $\mathrm{Na} / \mathrm{Cr}(\mathrm{mEq} / \mathrm{gCr})$ & 108.7 (91.1-159.8) & 119.6 (92.0-159.2) & 0.72 \\
\hline $\mathrm{K} / \mathrm{Cr}(\mathrm{mEq} / \mathrm{gCr})$ & $38.9(23.5-43.1)$ & $25.1(21.4-34.1)$ & 0.07 \\
\hline $\mathrm{Mg} / \mathrm{Cr}(\mathrm{mEq} / \mathrm{gCr})$ & $12.4(10.8-14.0)$ & $13.9(11.8-17.0)$ & 0.06 \\
\hline $\mathrm{NaCl}$ (g/day) & $6.0(5.4-7.3)$ & $4.7(4.2-5.5)$ & 0.0001 \\
\hline $\mathrm{Na} / \mathrm{K}$ & $4.2(3.4-5.2)$ & $4.7(3.8-6.5)$ & 0.11 \\
\hline & Obese/overweight $(n=13)$ & Healthy-weight $(n=62)$ & $p$ value \\
\hline Iso/Cr (nmol/mgCr) & $13.9(10.0-20.4)$ & $20.1(10.5-35.4)$ & 0.21 \\
\hline Tau/Cr (nmol/mgCr) & $596.0(482.5-956.9)$ & 778.6 (579.3-1041.4) & 0.22 \\
\hline
\end{tabular}

Values are presented as Median ( $25^{\text {th }}$ and $75^{\text {th }}$ percentiles) or Mean \pm Standard Deviation (SD). Wilcoxon test or unpaired $t$-test were used to compare each characteristic in each weight group.

Table 5 Selected urine biomarkers and estimated salt $(\mathrm{NaCl})$ intake on weekend and weekday 


\begin{tabular}{|c|c|c|c|}
\hline & Weekend $(n=81)$ & Weekday $(n=81)$ & $p$ value \\
\hline $\mathrm{pH}$ & $6.0(6.0-6.5)$ & $6.0(5.75-6.25)$ & 0.09 \\
\hline $\mathrm{UN}(\mathrm{mg} / \mathrm{dL})$ & $1250.8 \pm 291.8$ & $1218.9 \pm 344.5$ & 0.53 \\
\hline $\mathrm{Cr}(\mathrm{mg} / \mathrm{dL})$ & $123.1 \pm 42.9$ & $118.3 \pm 43.1$ & 0.48 \\
\hline $\mathrm{Na} / \mathrm{Cr}(\mathrm{mEq} / \mathrm{gCr})$ & $130.6(89.7-173.1)$ & $107.6(79.7-139.4)$ & 0.02 \\
\hline $\mathrm{K} / \mathrm{Cr}(\mathrm{mEq} / \mathrm{gCr})$ & $24.1(17.3-34.7)$ & $26.8(221.3-38.4)$ & 0.06 \\
\hline $\mathrm{Mg} / \mathrm{Cr}(\mathrm{mEq} / \mathrm{gCr})$ & $14.9(10.9-16.9)$ & $13.4(11.2-15.5)$ & 0.21 \\
\hline $\mathrm{NaCl}$ (g/day) & $5.2(4.3-6.2)$ & $4.8(4.0-5.6)$ & 0.10 \\
\hline \multirow[t]{2}{*}{$\mathrm{Na} / \mathrm{K}$} & $5.4(3.9-7.3)$ & $3.8(2.9-5.0)$ & $<0.0001$ \\
\hline & Weekend $(n=75)$ & Weekday $(n=75)$ & $p$ value \\
\hline $\mathrm{Iso} / \mathrm{Cr}$ (nmol/mgCr) & $12.5(5.7-28.9)$ & $21.5(12.1-36.6)$ & 0.0047 \\
\hline $\mathrm{Tau} / \mathrm{Cr}(\mathrm{nmol} / \mathrm{mgCr})$ & $716.3(422.6-1026.1)$ & $781.0(525.8-1028.4)$ & 0.32 \\
\hline
\end{tabular}

Values are presented as Median ( $25^{\text {th }}$ and $75^{\text {th }}$ percentiles) or Mean \pm Standard Deviation (SD). Wilcoxon test or unpaired $t$-test were used to compare each characteristic in groups as classified according to sample collection time points.

\section{Figures}


Spearman's rank correlation coefficient showing significant correlations between BMI and estimated salt intake (a), and between $\mathrm{BMI}$ and urine $\mathrm{Mg} / \mathrm{Cr}$ concentration (b), as evaluated by spot urine analyses. ${ }^{*} P<$ 0.05 .

\section{Figure 2}

Distribution of the value of estimated salt intake on weekend (a) and on weekday (b), as evaluated by spot urine analyses and calculated using Tanaka's equation [17]. 